\title{
Research
}

\section{Social Movements and Ecosystem Services-the Role of Social Network Structure in Protecting and Managing Urban Green Areas in Stockholm}

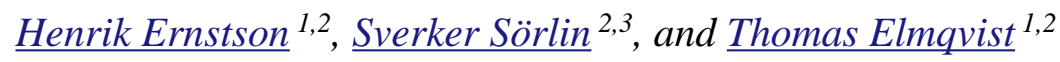

\begin{abstract}
Exploitation and degradation of urban green areas reduce their capacity to sustain ecosystem services. In protecting and managing these areas, research has increasingly focused on actors in civil society. Here, we analyzed an urban movement of 62 civil-society organizations - from user groups, such as boating clubs and allotment gardens, to culture and nature conservation groups - that have protected the Stockholm National Urban Park. We particularly focused on the social network structure of the movement, i.e., the patterns of interaction between movement organizations. The results reveal a core-periphery structure where core and semi-core organizations have deliberately built political connections to authorities, whereas the periphery gathers all user groups involved in day-to-day activities in the park. We show how the coreperiphery structure has facilitated collective action to protect the park, but we also suggest that the same social network structure might simultaneously have constrained collaborative ecosystem management. In particular, user groups with valuable local ecological knowledge have not been included in collaborative arenas. Our case points out the inherent double-nature of all social networks as they facilitate some collective actions, yet constrain others. The paper argues for incorporating social network structure in theories and applications of adaptive governance and co-management.
\end{abstract}

Key Words: adaptive governance; core-periphery structure; ecosystem management; social movements; social network analysis; urban ecosystem services

\section{INTRODUCTION}

Urban ecosystems are increasingly regarded as critical in providing ecosystem services of value for human health and well-being (sensu Daily 1997, Millennium Ecosystem Assessment (MA) 2005) such as mitigation of air pollution, noise, and heat, and provision of space for recreation and education (Bolund and Hunhammar 1999, McGranahan et al. 2005). Although it is accepted that fragmentation and isolation of green spaces leads to a loss of ecosystem services (e.g., Schwartz 1997, Young and Jarvis 2001, Stenhouse 2004), there is a need to better understand how social factors interact with urban landscapes and ecosystems to produce socialecological dynamics (Grimm et al. 2000, Alberti and Marzluff 2004, Redman et al. 2004), especially (i) why certain green areas, in the contested space of the city, remain, and others perish, and (ii) why some green areas hold higher ecological qualities due to differences in management practices.
Most research on urban green areas has focused on the formal planning process and on their protection and management (Drayton and Primack 1996, Chiesura 2004, Borgström et al. 2006, Sandström et al. 2006). Increasingly, however, attention has turned toward how groups in civil society and their respective management practices influence the spatial arrangements and quality of urban ecosystems, including for instance private gardens, golf courses, and allotment gardens (Barthel et al. 2005, Colding 2006, Colding et al. 2006, Andersson et al. 2007). Our study reinforces that "civic turn" and focuses on the Ecopark movement, an urban movement (cf. Castells 1983) that has protected the National Urban Park in Stockholm, Sweden. The movement, consisiting of some 60 civil-society organizations with approximately 10000 members, exemplifies that the protection of urban green areas rests on an active and organized civil society rather than on legislative powers. Actually, and as we have shown in another study (Ernstson and Sörlin 2009), 
it was the political actions of the movement that gave identity to the area and shaped the transformational change leading to its legal protection in 1995.

The movement, and similar forms of collective action, highlight crucial processes in civil society in both creating and providing protection for urban green areas (for other examples, see Diani 1995, Ansell 2003). As such, we can see them as partaking in social-ecological processes through shaping the city's ecological infrastructure and its capacity to generate ecosystem services. Therefore, our study focuses on how and why it has been possible for the movement to generate protective capacity for this green area and how this in turn has influenced its management. As we will show, however, social mechanisms that underpin protection of urban greens, might not always be favorable for their management.

In this paper, we employ social network theory (Wasserman and Faust 1994, Degenne and Forsé 1999) as it has been used in social movement theory (Diani 1992, 1995, Diani and McAdam 2003). These schools of thought and their methodologies can advance research on social-ecological systems, especially approaches that try to understand the role of social networks and social capital in adaptive forms of governance and co-management (Berkes et al. 2003, Adger et al. 2005, Dale and Onyx 2005, Bodin et al. 2006, Armitage 2007). Central to our study is an empirical investigation of the social network structure of the movement, i.e., the sustained pattern of interactions between movement organizations; a guiding thought is that such structures can simultaneously both facilitate and constrain collective action (Diani 2003c). Our paper offers insights as to how social networks may be studied and, more specifically, how such underlying structures facilitate or constrain collaborative ecosystem management and the protection of urban green areas. We also speculate on how they might influence the adaptive capacity of social-ecological systems (Folke et al. 2005).

Network analysis builds its explanations from patterns of relations between actors, and its greatest strength lies in the ability to analyze both the behavior of individual actors, and the behavior of the whole network (Emirbayer and Goodwin 1994). The actors in our research were social movement organizations (SMOs), defined as organizations that recognize each other as part of the same movement
(Diani 2003c). A presumption is that all relations of an SMO come with a cost, first for establishing it and then for sustaining it, which tends to direct information and resource flows following these patterns of established relations (Diani 2003a). In network language, this is translated as links between nodes in a graph, and as a basis for our study, we used four idealized network models shown in Fig. 1. Diani (2003c) explains that each model exhibits different characteristics. A "clique" movement requires all actors to invest a lot of time in networking with each other, thus drawing resources from interaction with outside actors, possibly leading to more closed communities with strong ideological or cultural affinities. The "wheel/star," or "core-periphery" structure, exhibits the contrary, where most actors can invest little time in networking but still remain close to others through the core actor. "Policephalous" structures suggest efforts to engage in collective action without delegating important tasks to a few centrally positioned actors, and "segmented-decentralized" structures reject any leaders to coordinate action on broader overarching concerns.

In relation to the whole network and the broader discussion on solving collective action problems (Leavitt 1951, Weimann 1982, Abrahamson and Rosenkopf 1997, Burt 2003, Reagans and McEvily 2003, Bodin and Norberg 2005), a core-periphery movement seems better suited for simple and easily identifiable tasks as information can be gathered by a set of a few actors who can coordinate and take action (Leavitt 1951). More segmented networks would be better at solving complex tasks (ibid.), whereas subgroups can generate independent knowledge for different parts and scales of the problem (Bodin et al. 2006).

However, and in relation to the behavior of individual actors, it is important to remember that social movements, and also more generally "communities," should be seen as heterogeneous entities with internal power struggles (Melucci 1996, Boström 2004). This means that the shape of the collective action that unfolds is influenced more by some actors than by others. In network analysis, this can be accounted for by recognizing that different network positions either facilitate or constrain actors (Diani 2003c: 303), and this can be measured by their degree and betweeness centralities (Freeman 1979). Actors with high betweeness centrality, i.e., with a tendency of sitting on network paths between many others, have greater 
Fig. 1. The figure shows four idealized network models for social movements (Diani 2003a:306ff). These arise from different levels of centralization and segmentation in the network, and are described in the main text. Nodes are actors and links are resource exchanges of some kind. Note that all actors in social movements have mutually recognized each other as part of the same movement. Figure adapted from Diani (2003a).

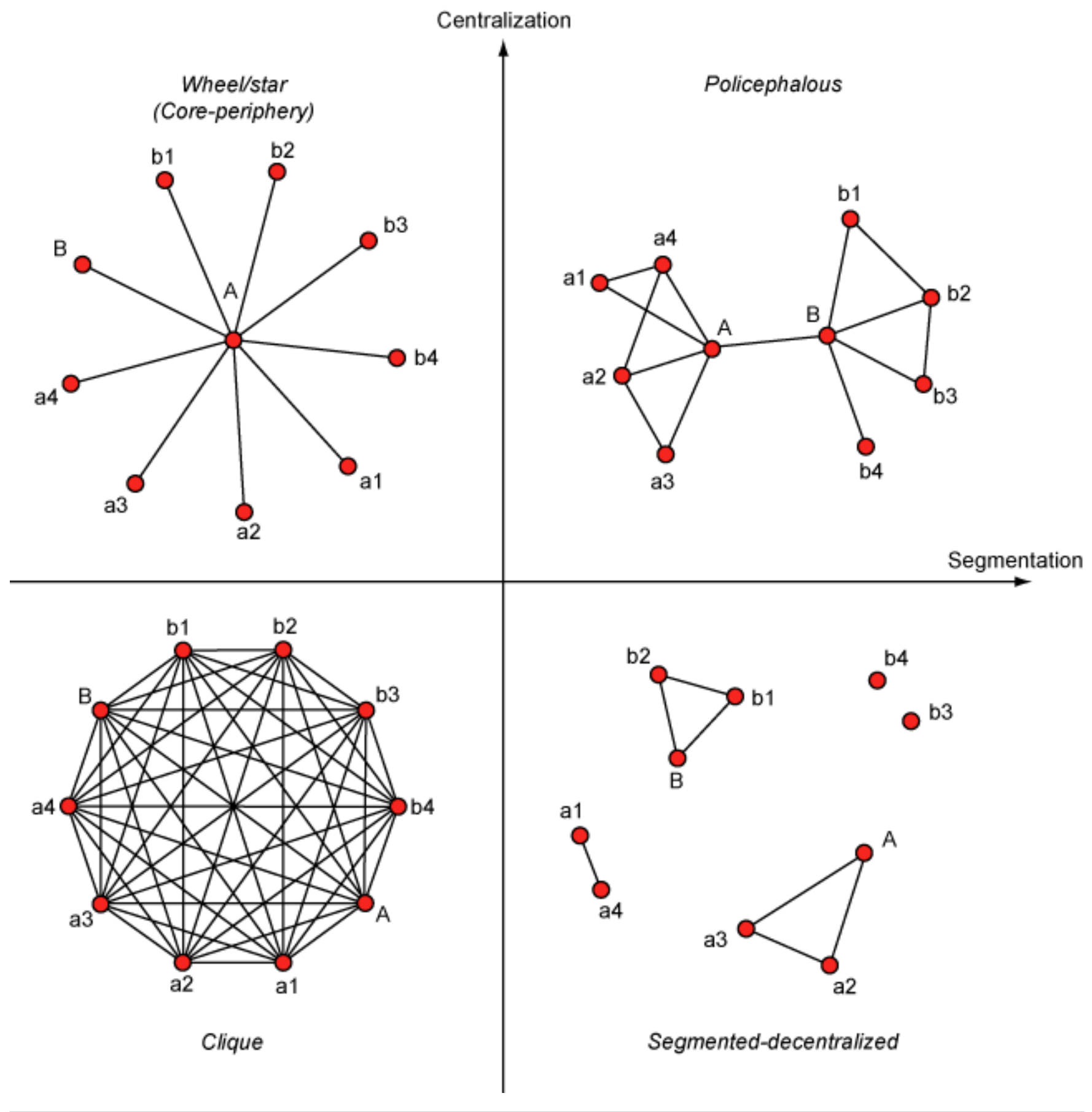


possibility to control the flow of resources. In Fig. 1 , this is illustrated by actor A (and B) in the policephalous model. For a high degree centrality (ibid.), the amount of in- and out-going links, is crucial because it measures how involved an actor is in the network and thus how known the actor is to others. This could increase the potential to locate and gain resources from the network, but also increase direct influence-for example, in face-toface meetings - and consequently the ability to shape actions and priorities (Diani 2003b). Actor a4 in the policephalous model of Fig. 1, has in this sense greater potential to influence the movement than $b 4$. To determine if this potential of influence is also translated to real power in the network, in our study, we will draw upon data from interviews and participatory observations.

Essential to our study are the user groups that participate in the movement. These are, for instance, allotment gardens, riding and boating clubs, scouts, ornithological associations, and sporting clubs, all having day-to-day activity of various degrees in the park. Although several studies point out their crucial role in collaborative ecosystem management, mainly through their potential possession of local ecological knowledge and attenuated abilities to monitor ecosystem change (Olsson and Folke 2001, Gadgil et al. 2003), few studies have accounted for how they are structurally embedded in social networks (but see Crona and Bodin 2006). This misses those important aspects of how and why user groups can participate or get excluded in deliberative processes, governance, and collaborative management, which we will analyze here.

Based on a social network survey, complemented by qualitative data, we address the following questions:

- What is the structure of the social network of the Ecopark movement and which of the typological network models from Fig. 1 provide best fit for our data?

- How does the structure affect the movement's ability to protect the park from exploitation?

- What accounts for the emergence of the observed social network structure? This is crucial to understanding the emergence of the area's protective capacity.
- Finally, how might the structure of the movement's network affect arenas for collaborative ecosystem management?

\section{BACKGROUND AND CONTEXT: TRANSFORMATIONAL CHANGE THROUGH A LOCAL URBAN MOVEMENT}

The National Urban Park is a $27-\mathrm{km}^{2}$ mixed woodland area close to the city center of Stockholm, Sweden (Fig. 2). Barthel et al. (2005) showed that the area's high biodiverstiy and its capacity to generate ecosystem services is tightly linked to the long-term use of the park by various user groups such as allotment gardens and by royal management stretching back hundreds of years. The park is also an important node in the city's ecological network (Löfvenhaft 2002, Elmqvist et al. 2004 and references therein). However, the proximity to Sweden's political, administrative, and business center results in a huge exploitation pressure from both municipalities, state, and building companies that has accelerated since the 1950s. Although voices for protection had been heard earlier, it was not until 1990, in reaction to a new set of plans for heavy development, that the Ecopark movement emerged (Ernstson and Sörlin 2009, details in Ernstson 2007). Originally, it began as part of a citywide cycle of protest events against a larger set of motorways and planned development at other sites in Stockholm (Stahre 2004).

Despite the movement's success in protecting the park through the law enacted in 1995, development plans continued to be made and the movement continues to mobilize protection efforts even today. This demonstrates not only the extreme levels of vested interests and conflicts characterizing urban landscapes, but also the social movement dynamics in that this set of individual organizations has come to link, across space and time, episodes of collective action into a longer-lasting effort (Diani 2003a, della Porta and Diani 2006: 23). Based on our prestudy and previous study (Ernstson and Sörlin 2009), we report on two important feats of the Ecopark movement in its early stages.

First, it constructed a novel vision for the area. Newly created organizations managed to frame a set of park areas in a novel way, baptizing them The Ecopark ("Ekoparken" in Swedish) and created a 
Fig. 2. The Stockholm National Urban Park (NUP; "Nationalstadsparken" in Swedish) lies close to the city center as shown in the map on the left. It stretches mainly into Stockholm and Solna municipalities, with a small part going into Lidingö. The map on the right shows the different historical areas of the park that were conceptually linked by the Ecopark movement (Ernstson and Sörlin 2008). Capital letters A-E mark sites for major planned development where the movement has been successful in stopping or altering the plans (see Table A2.1). For more information on the park's ecosystems and management, see Barthel et al. (2005) and Borgström et al. (2006).

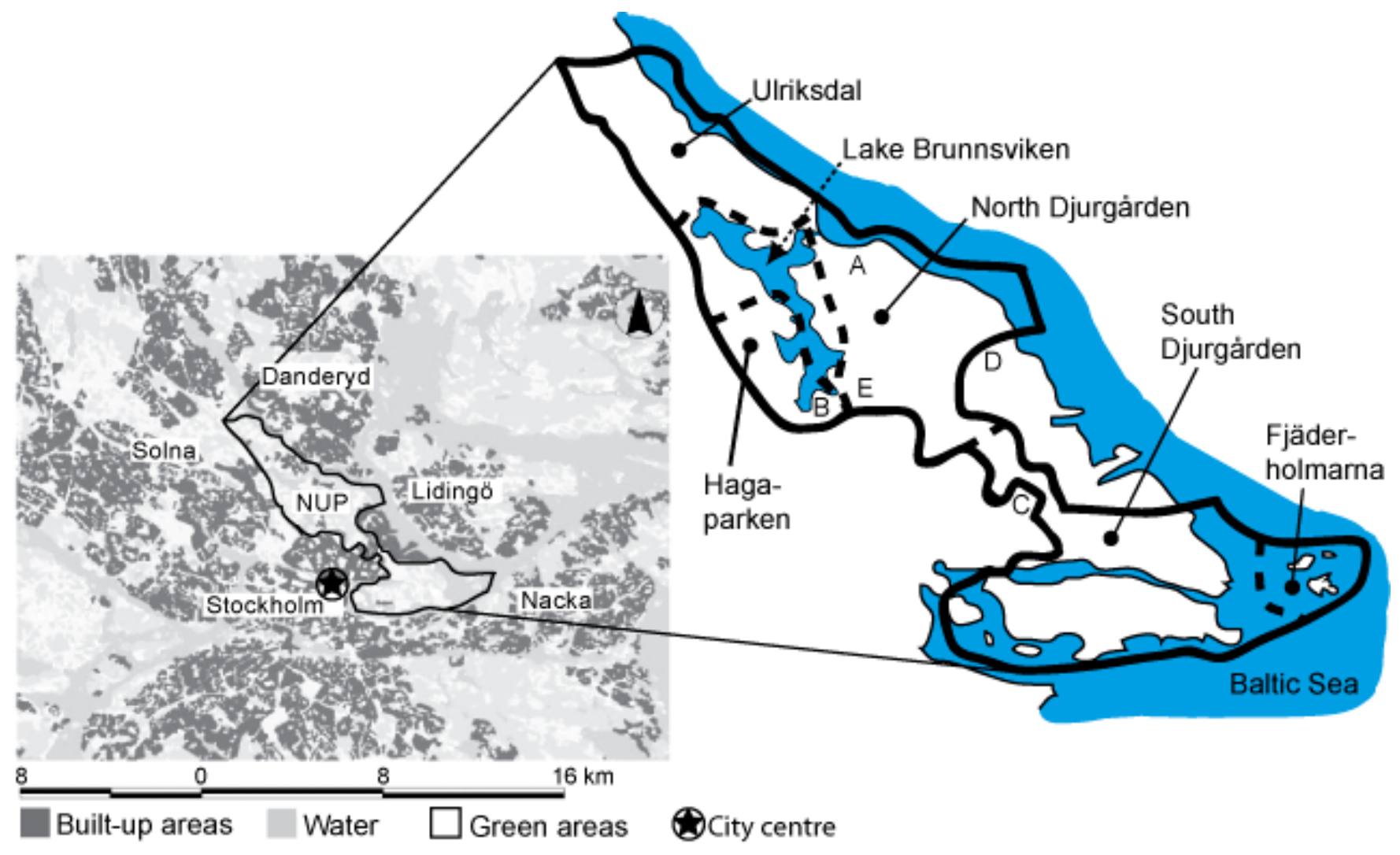

narrative able to explain that areas that before 1990 were viewed as unrelated, could be seen as connected (Ernstson and Sörlin 2009). In constructing their arguments, activists' efforts were facilitated by the abundance of artifacts associated with the area, largely due to its royal history. Both cultural historical artifacts (planned English parks, sculptures, castles, burial sites, runestones, etc.) and scientific artifacts from conservation biology (e.g., reports on core/buffer zones and species dispersal corridors) were employed to create a "protective story" (ibid.) that articulated the area's holistic values in which history and biology were seen as interlaced (ibid.). This framing process (Snow et al. 1986, Melucci 1995, Boström 2004) stretched the movement's identity over a greater spatial area, which was important in helping to mobilize a diverse set of organizations active in different parts of the Ecopark, (e.g., culture and nature conservation organizations, user groups, theatre groups). In 1992, 22 organizations created an umbrella organization, The Alliance of the Ecopark, that today brings together some 50 members. This organization became a focal point for movement activities, although some central organizations never became explicit members.

Second, building on the protective story and using its repertoire of developed methods (e.g., artist galas, exhibitions, lobbying), it managed to "jump 
scales" (Miller 2000) and move the political issue of the park from the local level of the municipalities to the national level, thus overriding the strong powers of the municipalities. In 1995, the protective law for the National Urban Park was passed (National Parliament 1994-1995).

Through its crucial role in establishing the law (Ernstson and Sörlin 2009), the Ecopark movement not only defined and constructed the identity of these green areas in Stockholm, but also transformed the governance structure of the park. Firstly, municipalities were forced to collaborate across borders, which opened ecosystem management up over an extensive landscape scale (cf. Nyström and Folke 2001). Secondly, the County Administrative Board was given the right to override the strong Swedish planning monopoly for municipalities, which opened up a new option for influencing the politics of the park. The latter shows how the movement, through its own actions, increased its political opportunity structure (cf. McAdam et al. 1996). Nonetheless, decision making on land-cover change is still highly centralized with the municipalities.

The Ecopark movement has clearly been engaged in a transformational change of a specific governance structure. Part of this rests on their vision building and up-scaling, which are factors identified in other studies of similar processes in the field of ecosystem management (Gunderson 1999, Olsson et al. 2004b). However, in contrast to these, we aim to uncover those social network mechanisms that underpin this type of collective action in this study.

\section{METHODS}

In this study, we viewed social networks as real observable phenomena (Marsden 1990, White and Houseman 2002). We denoted organizations within the Ecopark movement as nodes and measured the links between them by having respondents mark out their relations to other organizations. It is important to note that such self-reported ties are biased toward routine, typical interactions (Marsden 1990: 447 and references therein), implying that social networks should not be seen as snapshots in time, but rather as reflecting long-term stable patterns of social interaction (ibid.). This serves us well as our interest lies in capturing the dominant social processes involved in protecting the park. Below follows a description of our method; for more detail, refer to Appendix 1.

A robust method for generating self-reported ties is to use recall lists (ibid.), a list of all organizations in the field with adjoining empty columns in which respondents can mark their different relations to others (Diani 1992, 2003a). We created a recall list of all 92 organizations we found to have connections to the park. This list was sent to the official leader or another knowledgeable person in the 60 organizations that, based on our pre-study, seemed active in protecting the park (Appendix 1). Many organizations were members of the umbrella organization. Ansell (2003) used a similar approach, and although greater reliability could have been achieved by asking several activists per organization (as in Diani 1995), time and resource constraints made this unfeasible. In defining the boundary of the movement, we asked all respondents to mark those organizations that he or she affirmed as being active in the protection of the park. Organizations receiving at least two affirmations (mean 8.6, standard deviation (SD) 6.4, maximum 32) were selected as belonging to the movement, thus basing the boundary of the network on mutual recognition (Diani and McAdam 2003a: 10). This secured both a minimum notion of a shared identity (ibid.), but also had the advantage of allowing surveys to be sent to active organizations missed in the first set of 60 respondents. This happened for seven organizations. However, of these, all had only two affirmations, except one with three, and all received very few links from others (five were among the isolates with no links at all). Therefore, we decided not to send the surveys to these organizations as their impact on the analysis of the overall movement structure was deemed to be low. Our final set consisted of 62 social movement organizations (SMOs).

Using the recall list, we asked about four network relations: $(A)$ exchange of advice on cultural and political issues regarding the park; $(B)$ exchange of advice on nature and ecological issues; $(C)$ regular collaboration with other organizations; and $(D)$ if the respondent had personal friends in other organizations. These were chosen so as to capture information flow, coordination, and personal networks that we regarded as important in protecting a park framed by cultural history and conservation biology. Other scholars have used similar relations for similar movements (Diani 1995, Ansell 2003). Each respondent thus generated 
a row of ones and zeros for each of the four network relations; one symbolizing a relation to an organization, and zero signifying no relation. After having adjusted to account for a couple of respondents who had overestimated their out-going ties (Appendix 1), we assembled four 62 X 62 adjacency matrices, one for each network relation. We then turned the four relational networks into a single network $(N)$ through linear combination of the adjacency matrices. This increased the reliability of the final network as it relied on more data for each possible link (Marsden 1990), and also helped distinguish between strength of ties. To compensate for the leadership bias of our data (as it was based on asking only the official leader of each organization), we gave double weight to "collaboration with other organizations" when combining the networks. Thus, the final matrix addition was $N=A+B+2 C+D$. In the end, this produced a network with directional links that had strengths from zero to five (0-5). For some calculations, we transformed this network into a symmetrical and dichotomized network (i.e., no direction of links and no strengths, just zeros and ones; see Appendix 1).

At the same time, we generated data on SMO attributes suggested to influence network dynamics (see, e.g., McCarthy and Zald 1977, Diani 1995). These included membership size, number of activists, and type of funding. User intensity of the park was an attribute designed to gauge how much each SMO interacted with local ecosystems (see Introduction), by combining the number of days and type of activity that SMOs had reported. Political contacts were measured through a second recall list in which respondents marked contacts to formal organizations (e.g., municipal and state agencies). Scale of activity was based on asking where in the park (using a map) organizations had their main activities, but also through using secondary data (homepages and field documents). For example, allotment gardens are active inside the park, whereas the umbrella organization operates at the scale of the whole park. These attributes were used to find correlation patterns in the network structure.

To increase our ability to interpret the network structure, we also generated qualitative data focusing on the emergence of the movement, mobilization dynamics, and resources and methods used for protecting the park. Five interviewees were chosen from a list of most-cited activists generated out of the network survey, and we made four participatory observations at different meetings (for lists on interviews and observations, see Ernstson and Sörlin 2009). To sum up, 45 of the 62 organizations in the movement completed a survey, giving a response rate for the network analysis of $72.6 \%$. However, most analyses only concern the Main Component of 47 SMOs, increasing the response rate to $78.7 \%$. As mentioned earlier, the SMOs that did not complete a survey received few links and few affirmations of being active in the protection of the park. Therefore, we feel confident that we have a sufficiently valid data set, especially as we refrain from single-node analysis.

\section{RESULTS}

Merging the network survey's four relations yielded a sustained pattern of collaborative interaction between the diverse set of civil-society organizations in the Ecopark movement (Fig. 3). Regarding the network structure,we found a Main Component that displayed a core-periphery structure with three positions. The core and semicore positions were predominantly SMOs involved in nature and culture conservation with significantly higher mean levels of degree and betweeness centrality, as well as higher numbers of political contacts. The periphery position, with low centrality values and fewer political contacts, gathered those SMOs with significantly higher user intensity. Most peripheral actors were allotment gardens found (except one) either in the disconnected Gardening Component or among the 11 non-linked Isolates. For other attribute data, we found low correlations with degree centrality, except year of establishment, indicating that recently founded SMOs are slightly more central. High levels of segmentation outside the core and semi-core positions were only recorded among boating clubs and allotment gardens.

The results also underlined the impressive diversity of the movement. In interest and scale, the movement was found to range from voluntary local user groups, to national-level professionalized conservation organizations; over space, with SMOs from all parts of the park, even outside; and through time, with founding dates from 1885 to 2001 (tables and details found in Ernstson 2007 or 2008). From qualitative data, we identified a quite fixed repertoire of methods to influence decision making based on translating a set of identified resources into action (Appendix 2, Tables A2.2 and A2.3). Crucial resources were political contacts and activists' free- 
Fig. 3. The social network of the Ecopark movement consists of 62 organizations perceived as active in the protection of the National Urban Park by at least two respondents. They are divided in a Main Component (47 nodes), Gardening Component (4), and several unconnected Isolates (11). Also indicated is the Boating Cluster. The network is generally sparse and of low density; of the 2162 possible links, only 190 were realized in the valued network, whereas 119 were in the symmetrical network. Distances were nonetheless short, with an average of 2.33, and a maximum distance of 5 in the symmetrical network (of the Main Component).

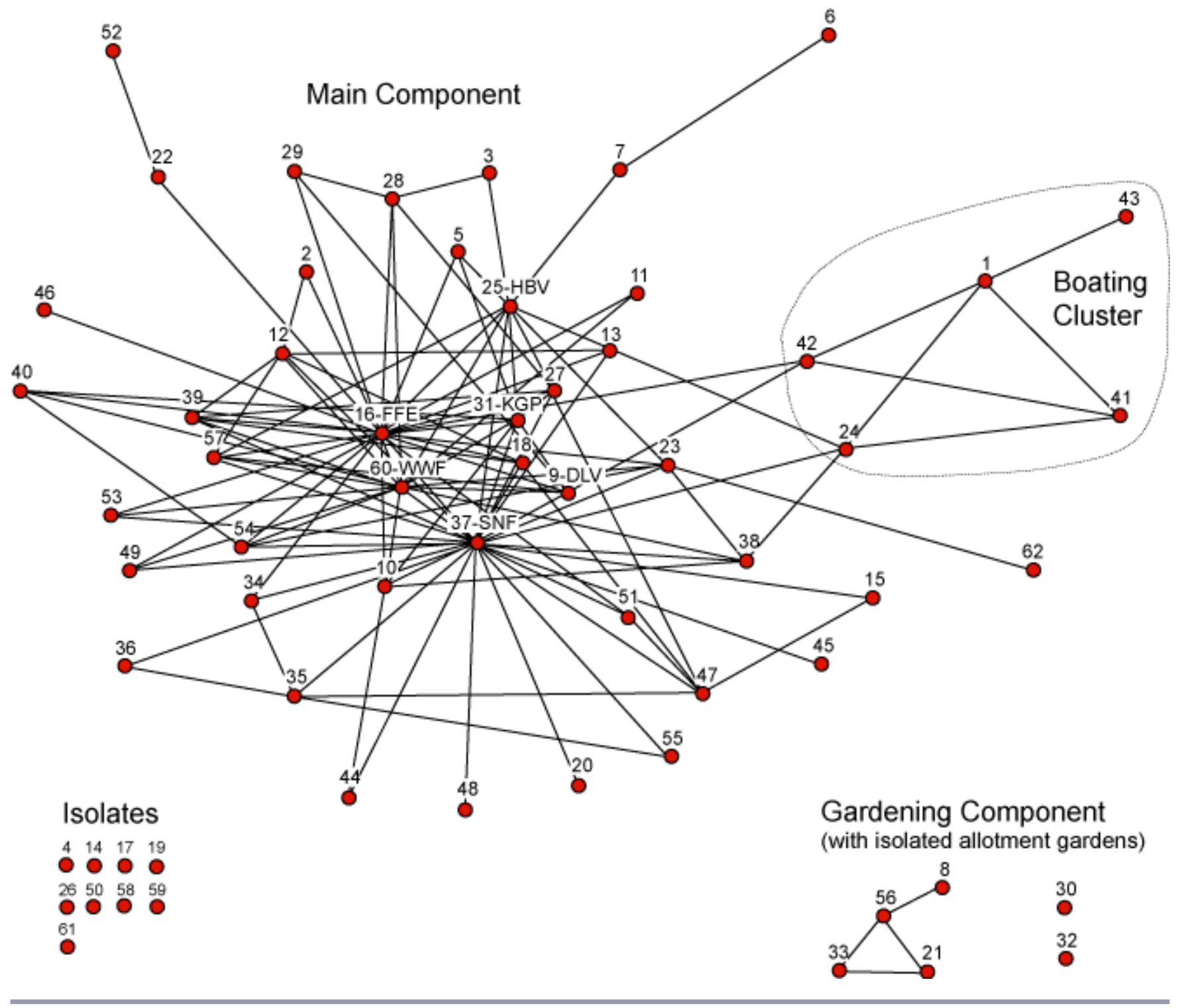


time labor, although two core SMOs had employed personnel.

\section{Block Modeling Based on Relational Data}

We simplified the movement's network-focusing on the Main Component - to better understand what social processes and mechanisms the network supports and constrains. This was done by searching for structurally equivalent actors (Lorrain and White 1971), which means finding actors with similar patterns of links to all other actors and grouping them into blocks. In the adjacency matrix, this means that actors with similar row and column vectors (out- and in-going links) are more structurally equivalent and could constitute a block. Using these blocks, a simpler network can be drawn that still preserves important structural aspects of the original network. Note that this simplification is not based on organizational attributes but exclusively on the SMOs' relationships to each other (Wasserman and Faust 1994). Attributes will be used in a second step to analyze how the movement's diversity is played out in the structure.

We used a technique based on the similarity of Euclidean distances in the valued network, followed by hierarchical clustering of these similarities (Appendix 1; Wasserman and Faust 1994: 363 for details). However, this procedure often proposes several possible block partitions, and it has been suggested that researchers should choose, guided by theory, one giving a meaningful interpretation (ibid.: 383). We chose a partition with three blocks in which Blocks 1 and 2 had three organizations each, and Block 3 gathered all other 41 SMOs. This selection was based on the fact that Blocks 1 and 2 remained the same for all possible partitions, whereas only Block 3 splintered into further subblocks (see partition diagram in Fig. A2.1 (Appendix 2)). Thus, the main structure of the movement, being our focus in this paper, was captured with three blocks.

Partitioning the Main Component's 47 X 47 network matrix according to the blocks-keeping the directions and strengths (0-5) of links-we calculated the link density between and inside blocks as the mean value of reported ties. This produced the block-model of Fig. 4. Blocks 1 and 2 differed in two aspects. First, Block 1 had almost maximal internal cohesion (4.67), whereas Block 2 was considerably lower (1.17). Second, Block 1 had more than four times as high link density to Block 3, than Block 2 (1.30 to 0.30). Comparing link densities between Block 1 and 3, the former showed twice as high link density to the latter than vice versa (1.30 to 0.58). In comparison with Block 3 , both Blocks 1 and 2 were extreme as their internal and in-between link densities ranged from 5 to 20 times higher than overall network density of 0.237 .

When exclusively comparing the Main Component with the movement models in Fig. 1, we made the following observations. The network is sparse, directly ruling out the clique model, and furthermore, as all actors are connected, we also ruled out the segmented-centralized model. With these excluded and with high network centralization, it seemed that our data best fit the wheel/star (coreperiphery) structure. Block 1 clearly occupied the core position, being most active in sending links and most recognized by the others. Importantly the block had also high internal density, making the three organizations of Block 1 resemble the core actor in Fig. 1. Block 3, being more loosely linked to the others, constituted the periphery position as it had extremely low internal link density indicating low segmentation, a trademark for periphery positions.

However, the network departed in two ways from a classic core-periphery structure (Borgatti and Everett 1999). First, in the classic outline, periphery actors send more links to the core than vice versa, explained theoretically through their greater interest in the concentrated resources of the core (ibid.). Here, we had the opposite situation, pointing out that valuable resources also resided in the periphery. Second, we had one extra block, Block 2. As it had too low internal link density, Block 2 could not be a core. At the same time, it was generally more recognized as having more incoming links than Block 3, and furthermore, it had much higher interaction with the core actors of Block 1 than with the periphery actors of Block 3. Block 2 was thus socially closer to the core, which made us dub it the semi-core position. The policephalous model, finally, could have been the best-fit model if Block 2 had shown more links to the periphery. As it was, the network was mostly held together by Block 1 , being thus rightfully seen as the core. 
Fig. 4. The figure shows the simplified movement network reached through a block model of the Main Component with three structurally equivalent positions (Blocks 1-3). The blocks were dubbed core, semi-core, and periphery position, respectively, and contained the following SMOs: Block $1=[\mathrm{N} 16$, N37, N60]; Block 2 = [N9, N25, N31]. Block 3 contained all 41 other SMOs.

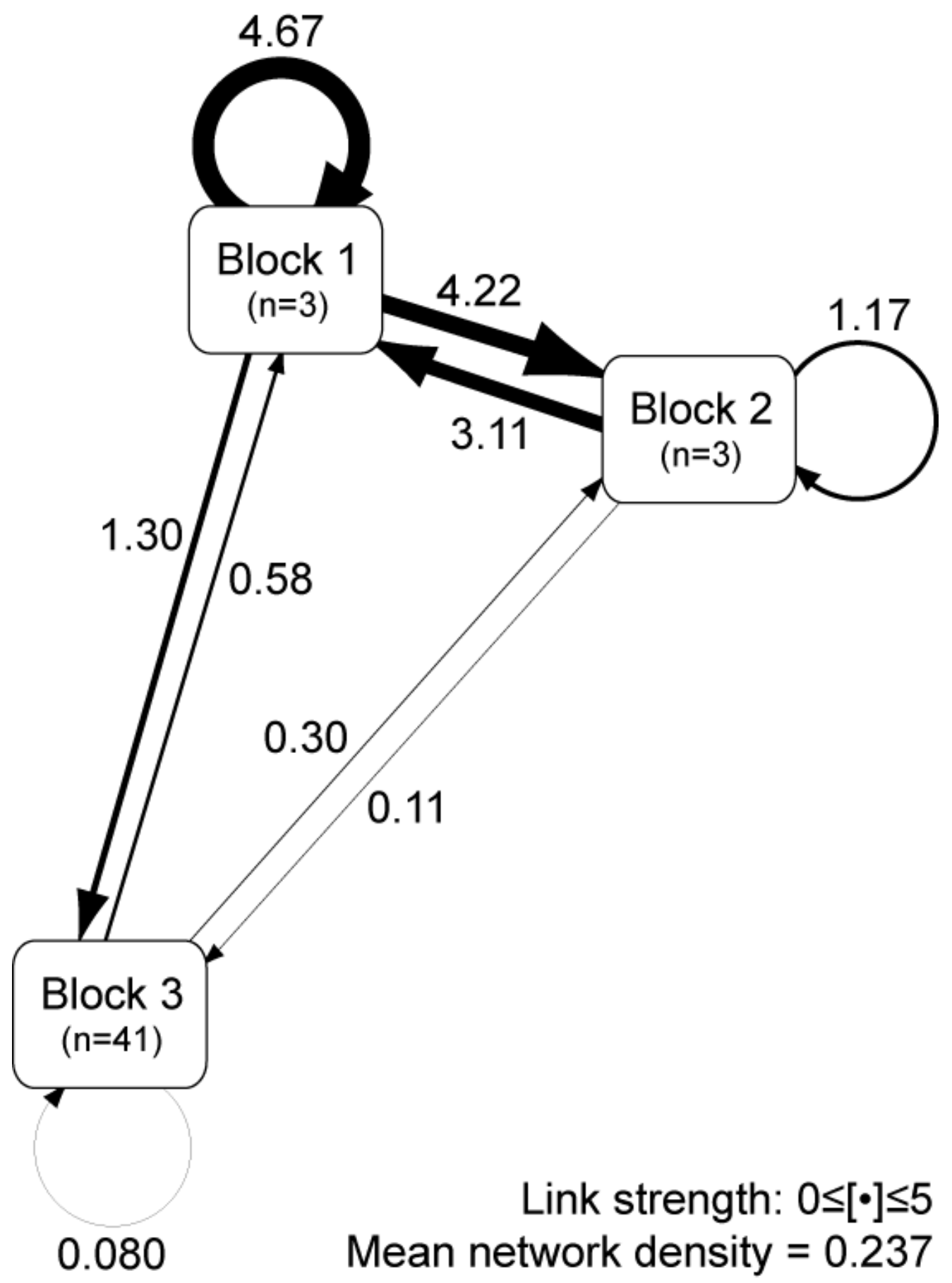




\section{Correlation Analysis}

Before reporting on the distribution of organizational attributes, we first note from Table 1 that degree and betweeness centrality were significantly and strongly correlated in the Main Component. A general characteristic of the network was thus that those actors directly connected to many others (high degree centrality) also tended to sit on paths between many others, i.e., with high potential to control resource flows (high betweeness centrality). Centrality is moreover strongly skewed. The three organizations with highest degree centralities - also being the core actors found above (N16, N37, N60)—were involved in 30\% of all existing symmetrical ties, giving further support to the notion of a core-periphery model for the network. Correlating other attributes with degree centrality, we only found a strong and significant correlation with number of political contacts, whereas a weaker and less significant correlation was found with year of establishment (Table 1). Both these supported our pre-study finding that newly formed and more politically active organizations had played an active role in creating and sustaining the movement (also supported in field documents, see Ernstson 2007).

\section{Distribution of Organizational Attributes in the Structure}

In Table 2, we have summarized how the most important organizational attributes were distributed across the core-periphery structure. Not surprisingly, the core and semi-core positions had significantly higher mean values of degree (and betweeness) centrality than the periphery; not even the periphery's maximum value of seven reached this. Regarding number of political contacts, core members had exceptionally high numbers, followed by semi-core members. Periphery members had on average significantly lower amount of political contacts, although three (out of 41) had a higher amount than the semi-core's average value of 20.7 , and a further six were found in the interval between 14-18. This pointed out that in order to be a member of the semi-core - and not the periphery - an SMO needed not only many political contacts, but also many links to core members. Another important trend was the distribution of the scale of activity, with core actors active on the scale of the park or above, and semi-core and periphery actors having activities predominantly on scales inside the park.

All user groups in the Main Component were found in the periphery position. This suggested that SMOs with high user intensity, those potentially rich in local ecological knowledge, tended to occupy positions that gave them less potential to influence the movement. To test if data in the Main Component supported this, we took all user groups in the periphery position with high user intensity $(U i \geq 30)$ and created Block 4 (thus disregarding strict structural equivalence for this block). An analysis of variance (ANOVA) proved that Block 4 had significantly higher mean user intensity than other blocks (Table 2), supporting our suggestion. Here, Block 1 scored second with less than half the value, whereas Blocks 3 and 4 had much lower user intensities. However, the relatively high user intensity of Block 1 came from just one SMO, the World Wildlife Fund (WWF). When this outlier was removed, the user intensity of Block 1 dropped tenfold (106.7 to 10 user-intense days per year). As our aim was to determine the pattern of where user groups were located in the network structure, we can justify the removal of the WWF based on our qualitative data, which informed us that the WWF is not a user group in the same sense as, for example, boating clubs or allotment gardens. These can have as many as 100 volunteer members, whereas in contrast, the Ecopark Fund WWF is a professional project under the WWF run, in effect, by one employee.

Finally, referring to the whole movement network, we observed that all user groups, following the trend uncovered in the previous paragraph, were considerably marginalized in the movement. Most marginalized were the six allotment gardens; two were found among the Isolates, three in the disconnected Gardening Component, and one in the periphery position. The Gardening Component consisted of three allotment gardens (and a loosely connected theatre organization), including notably the umbrella organization for all allotment gardens in Stockholm (N21). Network segmentation was also found in the Main Component, where a community analysis (Girvan and Newman 2002) revealed a Boating Cluster consisting of all existing boating clubs (N1, N24, N41, N42, N43). However, the general result for the Main Component was that 
Table 1. The table gives correlation values between degree centrality and selected SMO attributes in the Main Component. For other organizational attributes in the study, correlation values gave too large $p$ values to be significant. Number of nodes for all calculations was $47(N=47)$.

\begin{tabular}{lrrrrrrrr}
\hline \hline Attribute & $\begin{array}{l}\text { Correlation with } \\
\text { degree centrality }\end{array}$ & $P$ value & $\begin{array}{r}\text { Missing } \\
\text { data }\end{array}$ & Min. & Max. & Median & Mean Std. dev. \\
\hline Degree centrality & - & - & 0 & 1 & 29 & 3 & 5.1 & 5.7 \\
Betweeness centrality & $0.859^{* * *}$ & $1.110^{-14}$ & 0 & 0 & 0.43 & 0.002 & 0.03 & 0.08 \\
Political contacts & $0.708^{* * *}$ & $1.210^{-6}$ & 11 & 0 & 70 & 5 & 12.5 & 16.1 \\
Year of establishment & $0.302^{*}$ & 0.0551 & 6 & 1885 & 2001 & 1973 & 1955 & 37.1 \\
$\begin{array}{l}\text { Affirmations of being active in } \\
\text { protecting the park }\end{array}$ & $0.776^{* * *}$ & $1.510^{-10}$ & 0 & 2 & 32 & 6 & 8.6 & 6.4 \\
\hline
\end{tabular}

segmentation was low, showing that most organizations interacted regardless of their main interest or other attribute.

\section{DISCUSSION}

In this study, we investigated why a set of civil society organizations played a crucial role in protecting the Stockholm National Urban Park, and as such, influenced the ability of this urban landscape to generate ecosystem services. By conducting a social network analysis, we show that the Ecopark movement consists of a social network that links a diverse set of actors. This network took shape at the beginning of the 1990s when newly formed organizations mobilized against large-scale development plans. By constructing a holistic vision of the park that included a greater connected geographical area, other groups in the area were also mobilized. The movement displays a wheel/star or core-periphery structure with three positions: core, semi-core, and periphery (Fig. 4), and two attributes, political contacts and user intensity, emerge as important descriptive factors (Table 2). A high level of political contacts correlates with many links to other SMOs, whereas high user intensity characterizes less central SMOs with fewer political contacts. By bringing this together, we produced the image in Fig. 5, which displays how the movement, in its struggle to protect the park, has come to link the decision makers of the park with its ecological systems.
Previous studies show that environmental movements often match core-periphery profiles (Ansell 2003, Diani 2003c), and empirical studies of environmental movements in Britain and Milan, Italy have shown how core actors function as bridges to local actors (Lowe and Goyder 1983, Diani 1995). This resembles our findings with core actors active on the scale of the park or above, and semi-core and periphery actors predominately active at lower scales (Table 2). An important parallel is also found from research on self-emerged collaborative ecosystem management, where Hahn et al. (2006) report-although not assessed through formal network analysis-core-periphery structures in which "bridging organizations" link, as in our case, between the politics of land use and user groups. We will use the movement's network structure as basis to discuss social mechanisms facilitated and constrained by social networks.

\section{The Ecopark Movement_a Scale-Bridging Local Movement}

Diversity is important, but it is the structure of diversity that transforms it into collective action. We argue that the high organizational diversity found in the Ecopark movement, based in turn on the diversity of organizations attracted to the National Urban Park area, underpins protective capacity. But, we further argue that it is the structure of this diversity that transforms into action and materializes protection. In Table 3, we have 
Table 2. The table describes the structural positions in the Main Component through the distribution of SMO attributes. The members of Block 4 are not strictly structurally equivalent, but a subset of heavy user groups from Block 3 (Ui $\geq 30$ ). Note: $[\mathrm{v}]$ and $[\mathrm{s}]$ mean that the valued and symmetrical networks, respectively, were used for calculations; [1] and [2] mean that the user intensity was calculated with and without the outlier WWF, respectively. The number of missing data for each calculation is given within parenthesis $(\mathrm{NaN})$.

\begin{tabular}{|c|c|c|c|c|c|c|}
\hline Measure & $\begin{array}{l}\text { Block } 1 \\
\text { Mean (NaN) }\end{array}$ & $\begin{array}{c}\text { Block } 2 \\
\text { Mean }(\mathrm{NaN})\end{array}$ & $\begin{array}{c}\text { Block } 3 \\
\text { Mean (NaN) }\end{array}$ & $\begin{array}{c}\text { Block } 4 \\
\text { Mean (NaN) }\end{array}$ & $\begin{array}{c}\text { ANOVA } \\
\text { F }\end{array}$ & $P$ value \\
\hline Degree centrality $[v]$ & $117.7(0)$ & $43.3(0)$ & $13.2(0)$ & - & $131 * * *$ & $3.210^{-19}$ \\
\hline Degree centrality[s] & $24.0(0)$ & $9.33(0)$ & $3.37(0)$ & - & $116 * * *$ & $2.710^{-18}$ \\
\hline Betweeness centrality $[\mathrm{s}]$ & $0.28(0)$ & $0.056(0)$ & $0.0092(0)$ & - & $48.2 * * *$ & $8.110^{-12}$ \\
\hline No. of political contacts & $51.7(0)$ & $20.7(0)$ & $7.3(11)$ & - & $27.6^{* * *}$ & $9.210^{-8}$ \\
\hline User intensity[1] & $106.7(0)$ & $3.3(0)$ & $3.3(9)$ & $231(0)$ & $4.55^{* *}$ & 0.00876 \\
\hline User intensity[2] & $10(1)$ & $3.3(0)$ & $3.3(9)$ & $231(0)$ & $4.74 * *$ & 0.00738 \\
\hline Year of establishment & $1986(0)$ & $1988(0)$ & $1950(6)$ & - & $2.76^{*}$ & 0.0758 \\
\hline No. of SMOs & 3 & 3 & 41 & - & & \\
\hline No. of SMOs & 3 & 3 & 30 & 11 & & \\
\hline Type of organization & $\begin{array}{l}1 \text { voluntary } \\
2 \text { professional }\end{array}$ & All voluntary & $\begin{array}{l}39 \text { voluntary } \\
2 \text { professional }\end{array}$ & All voluntary & & \\
\hline Main interest & $\begin{array}{l}\text { Culture/nature } \\
\text { conservation }\end{array}$ & $\begin{array}{l}\text { Culture/nature } \\
\text { conservation (one } \\
\text { env.prot.) }\end{array}$ & Mixed & $\begin{array}{l}\text { User groups } \\
(U i \geq 30)\end{array}$ & & \\
\hline Scale of activity & $\begin{array}{l}2 \text { whole-park } \\
1 \text { city-regional }\end{array}$ & $\begin{array}{l}\text { All locally inside } \\
\text { park }\end{array}$ & $\begin{array}{l}20 \text { (of } 41 \text { ) locally } \\
\text { inside park }\end{array}$ & $\begin{array}{l}10 \text { locally } \\
\text { inside park }\end{array}$ & & \\
\hline
\end{tabular}

summarized the two protective functionsstopping large- and small-scale development-that the movement has created and maintained (A1-A2), the structural network factors that underpin these (B1-B5), and the factors responsible for the emergence and reproduction of the core-periphery structure $(\mathrm{C} 1-\mathrm{C} 5)$. We discuss these in the sections below in pursuit of the social mechanism responsible for protective capacity.

\section{Dense social arenas and coordination of collective action}

The dense social arena between core and semi-core actors is key to understanding the movement's success, and it also represents a perfect playground for collective learning. Theories on collective action tells us that high link density, or strong ties, is a sign of reciprocity and trust that facilitates collective action by lowering the cost and risk of collaboration 
Fig. 5. Through their struggle to protect the National Urban Park, the Ecopark movement has come to link the politics of the park with its ecosystems. Core and semi-core actors connect to decision makers through many political contacts, whereas peripheral actors have higher user intensity and more day-today activity in the park. The values are taken from Table 2, with the WWF removed, as discussed in the main text.

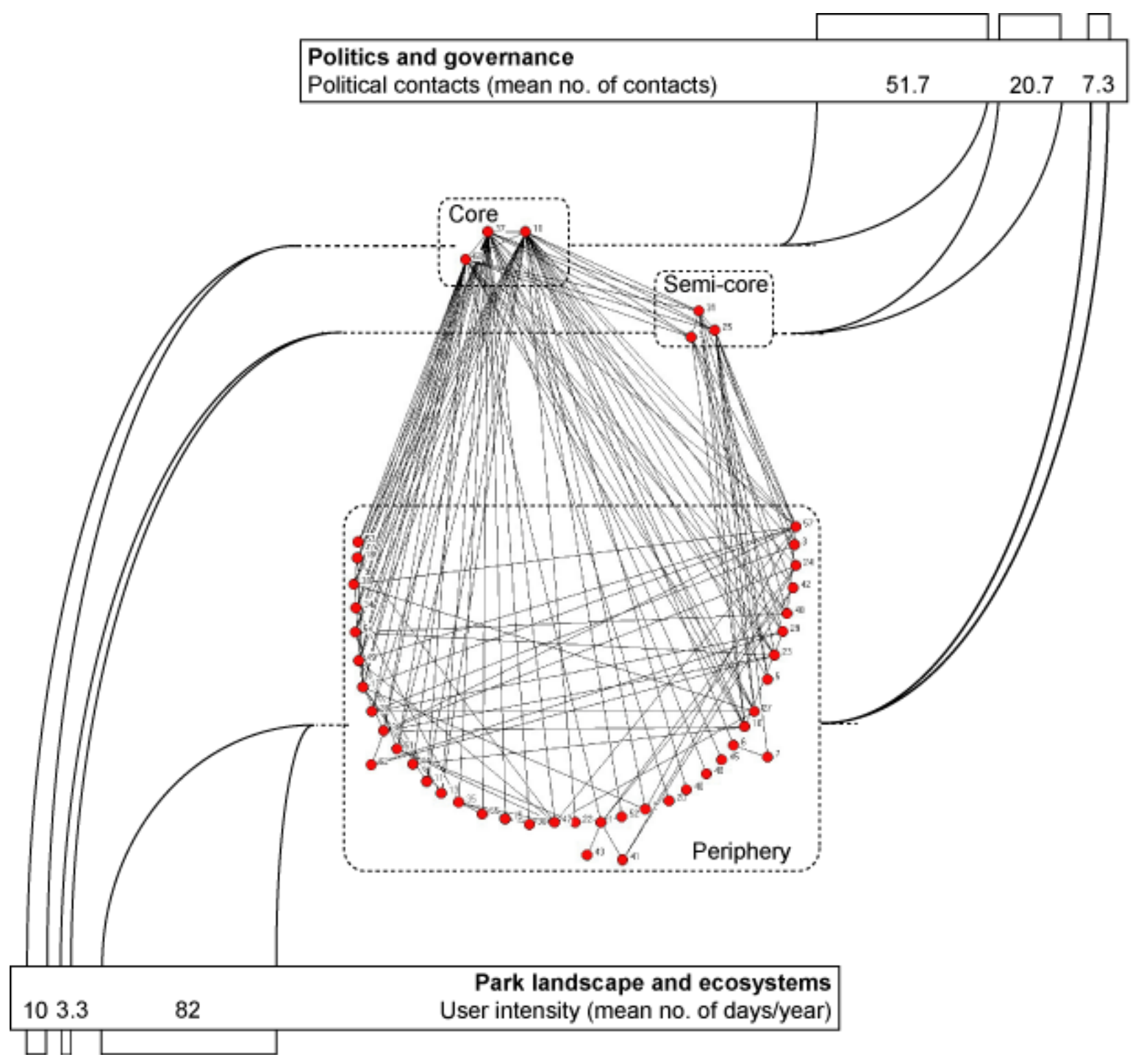


Table 3. This table summarizes our findings in the following way: the Ecopark movement upholds two protective functions (A), which are facilitated through five structural network factors (B). There are further five factors that can explain the emergence and reproduction of this structure $(\mathrm{C})$. The table can be read as follows: $\mathrm{C}$ has given rise to $\mathrm{B}$, which in turn sustains $\mathrm{A}$.

\section{Function/factor \\ A. Protective functions \\ A1. Stopping large-scale development}

Description

A2. Stopping small-scale development

\section{B. Structural network factors \\ B1. Integration of information}

B2. Dense social arena

B3. Brokerage and coordination

B4. Internal bridging links (sustaining diversity)

B5. Political contacts (external bridging links)

\section{Emergence factors}

C1. Diversity of civil-society groups

\section{C2. Politically active organizations} C3. Holistic vision and
protective story

C4. Centralized institutional context

C5. Self-reinforcing mechanism
Large-scale development plans are a public process centralized around the municipalities, with public consultation meetings before a decision is made by the municipal parliament.

Small-scale development occurs in an ad hoc fashion, and without the necessary approval from the municipal parliament; for monitoring, small-scale development represents a more distributive process.

Core-periphery structures tend to integrate information to core actors (Leavitt 1951),
which gives them access to relevant information from the network.

The dense social arena between core and semi-core actors captures experience over time and facilitates collective learning and the development and sustaining of protective methods (Wenger 1998, Borgatti and Foster 2003).

The brokerage position of the core actors facilitates coordination of the movement as they have access to early and non-redundant information (Burt 2003).

The links between core and periphery, especially to the user groups, bridges spatial, temporal, and jurisdictional scales. This increases the legitimacy of the political project and increases ability to detect small-scale development.

The many links that core and semi-core actors have to authorities and formal actors, i.e., political contacts, give them both early access to information and channels to influence the decision-making process.

The park area has over time attracted a wide range of different user and interest groups, probably related to the various landscape types found in the park.

A set of new organizations were formed that had a clear political objective to stop development plans and protect the park

In taking purposeful action to protect the park, the newly formed organizations constructed a protective story that linked park areas into a holistic vision and mobilized organizations with activities and interests in the park (Ernstson and Sörlin 2008).

The centralized institutional decision-making process on land-cover change has reinforced the core-periphery structure (Leavitt 1951), a tendency enhanced by the place-based character of the struggle (Ansell 2003).

The core-periphery structure tends to reinforce core and semi-core actors' control over vital resources, which in turn reproduces the structure (cf. Diani 2003c). 
(Granovetter 1973, 1985, Ostrom 1990, Burt 2003). It also facilitates the transfer of tacit or experiencebased knowledge, a notion especially developed in theories on "communities of practice" and social learning (Wenger 1998) and explored in network studies (Borgatti and Foster 2003: 997, Reagans and McEvily 2003). Through such dense social arenas, social practices on what to do and how to do it can develop and be sustained, and guide interactions within and outside the community. In our case, this arena has helped capture in-flowing information (through weak ties) from both the movement's network and political contacts, so that it can be turned into fine-tuned knowledge about the decision-making process on land-cover change, and on how and when this process can be influenced. As such, the "strength of weak ties" depends on dense social arenas of strong ties (Granovetter 1973, Newman and Dale 2005). In support of this, we noted, as activists explained how they went about protecting the park, their detailed knowledge on the decision-making process and the skills and resources of other core and semi-core activists. This included knowledge concerning state agencies involved in land-use decisions, friends and foes within these, and the laws that could be useful in obstructing development, but also who within the movement holds knowledge on ecology, or legal loopholes, or has contacts to power-holders. Therefore, we interpret the movement's repertoire of methods (Table A2.2) as an outcome from an iterative trial-and-error process through earlier struggles, an outcome facilitated by the dense social arena as it captures and also socializes gained experience into prescribed practices, i.e., methods.

Coordination of collective action is also facilitated through the core-periphery structure as it turns core actors into brokers. Brokers, as explained by Burt (2003, 2005), have a structural advantage based on their exclusive links to actors that are not directly linked to each other. This implies that they gain access to many more pieces of information captured inside different actors to continously be able to synthesize more information. The advantage thus emerges from the larger structure, and is not dependent directly on certain attributes of the organization. Through this, the broker gains what Burt calls adapative implementation, an ability to navigate in a continously changing social landscape and coordinate the actions of a network, and learn which actors can be depended on in times of action, knowing whom to connect (and not to connect), how to connect them, and when. In our field work, we encountered several examples of this performed by core and semi-core actors, for instance when they were mobilizing in direct reaction to development plans. This demanded coordination of a row of sequential activities that they often divided amongst themselves, sometimes — it seemed-without actually meeting, giving further credit to the capacity of dense social arena to socialize experience. The activities also included interacting and mobilizing certain periphery organizations found suitable for the situation (for details, see Ernstson (2007)). As we will return to below, this is also a question of power in which core and semi-core actors shape to a greater extent than others-whether consciously or not - the collective action that unfolds.

\section{Network diversity and stopping small-scale development}

Core actors send on average more links to the periphery than vice versa, pointing out that core members find valuable resources in the periphery. We suggest two reasons for the core's interest in the periphery. First, these links sustain overall political legitimacy for the movement because representing a large and diverse field of organizations is a political asset, especially for core and semi-core actors, when meeting with the media and authorities. As pointed out by a core activist: "Our strength lies in being able to keep so many different interests together." Second, these links sustain a protective mechanism for small-scale development that would otherwise be difficult to handle, and which we discuss here.

Large-scale development plans must take the centrally structured route through the municipalities and are thus easily detectable by core and semi-core members through their many political contacts. However, small-scale development, e.g., car-parks, sheds, or the felling of individual trees as mentioned in the interviews, does not need to be handled by the municipalities and could be missed. However, and as captured in an interview with a core activist, these can be detected by people who spend time in the park:

[...] there are many things going on in the park. It can for example be that Solna municipality starts a very rough restoration of the Tivoli Park, and we are not out in the Tivoli Park all the time. So it all boils down to that somebody that lives in the neighborhood and happens to be a member 


\section{of the [umbrella organization] can notify us and sound the alarm.}

As periphery members are spread out geographically and have higher user intensity, they spend more time in the park than core and semi-core actors and are better able to monitor such small-scale development. The core actors can make use of this information and take effective action through their developed methods, something out of reach for peripheral actors. We see how the links between core and peripheral user groups sustain a protective mechanism that links across spatial scales (cf. Adger et al. 2005, Borgström et al. 2006). Seen over a longer time perspective, this protective mechanism is of additional importance. Here, we refer to what activists call "the tyranny of small steps," which includes both occasional small-scale development, but also the sequence by which green areas are slowly degraded by small-scale activities. Such sequences could for instance start when public events are held in the park (e.g., circus, theatre, concerts, running competitions) and lead to the grassland, through repeated use over years and even decades, being slowly turned into beat-up soil. As pointed out by one experienced core activist, green areas can be completely lost in this way. A typical example was a green field that was first used to stage a public event and then gradually lost as municipal workers started parking their cars there, first covering it with gravel and some time later with asphalt, turning it into a "functional" carpark.

\section{The Emergence and Reproduction of Social Network Structure}

Social network structures are patterns left by dominant social processes (Marsden 1990: 447 and references therein) and thus retain clues to the social mechanisms responsible for their emergence and reproduction. Here, we make use of this to find factors explaining the core-periphery structure of the movement and the emergence of the area's protective capacity (C1-C5 in Table 3$)$.

From 1885 until today, a growing number of organizations with different interests and activities have found their home in the park area, both interest and user groups. As proposed by our findings, and supported by Barthel et al. (2005), this suggests an interesting link between the geological and ecological characteristics of a place and the potential to protect and management it; a diverse landscape, such as in the Stockholm National Urban Park, with open fields, deep forests, and water surfaces, can sustain a greater range of different activities and attract more organizations, which could facilitate collective action toward protection and management capacity. Another reason for the high organizational diversity probably lies in the growing city that, on one hand, serves as a source of members for these organizations, but on the other, also constantly diminishes the total amount of green space available, thus increasing the number of organizations active in each remnant area.

However, as we have shown above, the coreperiphery structure is crucial for protective capacity, which directs us toward the politically active organizations that mobilized the diversity of organizations. These were purposefully created for political struggle by activists who already had political contacts, or gained them during their course of action. As pointed out in interviews, the older organizations (many based on user activities) were either not known of or not regarded as fit for political action. As mobilization picked up, older organizations were notwithstanding seen as an asset to increase political legitimacy. Furthermore, protection efforts were mediated through a centralized institutional setting in which municipalities have a monopoly on land-use decisions (cf. Leavitt 1951, Borgatti and Everett 1999). Taken together, these factors account for the emergence of a coreperiphery structure. During this process, it was only the allotment gardens that formed their own component (Fig. 3), explained partly through their already established relations to their own umbrella organization (N21), active at the scale of the city.

This core-periphery structure has then tended to reinforce itself. Core and semi-core actors have, as we have seen, a position that allows them to take earlier and more effective action. This reinforces their control over valuable resources such as political contacts and information, while sustaining internal movement links. This explains the high correlation we found between degree centrality and political contacts, and we argue that this combined effect gives core and semi-core actors' greater real influence in the movement, i.e., more power. We stress that this need not be true for all movements; in movements dependent on direct action or mass media, many links to others might be less important. In further support, we also note that the movement's methods-based on qualitative data-center around the access to information (gained through 
having many links) and political contacts (Tables A2.2 and A2.3 in Appendix 2).

The structure sustains a self-reinforcing network mechanism. This has been observed in other network studies (Diani 1995, Ansell 2003, Diani 2003c) and Diani (2003a: 311) argues that once movements reach a core-periphery structure, they tend to become politically settled and content with the political goals of the core actors. Ansell (2003) also suggests that place-based movements have fewer tendencies toward segmentation and cleavage, as goals need to be tied to a physical place and not to abstract principles as in issue-based movements (e.g., the feminist or global justice movement). There are factors explaining the generally low segmentation in the movement. However, segmentation exist and becomes of crucial concern below.

\section{Social Network Structure and Collaborative Ecosystem Management}

Important prerequisites for collaborative ecosystem management are fulfilled by the Ecopark movement (Barthel et al. 2005). There is high organizational diversity (to negotiate the stakes), a multitude of user groups (to have access to ecological feedbacks), and a social network (to facilitate information flows) (Berkes et al. 2003, Olsson et al. 2004a, Fabricius et al. 2007). However, we have empirical evidence that user groups do not participate in existing collaborative arenas and consequently that all stakeholders are not represented, and perhaps more crucially, that there is less access to ecological feedbacks. Instead, core and semi-core groups - with few days of activity in the park-are highly represented. The clearest indication is that, in the official coordination group of the park, led by the County Administrative Board, there are no user groups but only core and semi-core actors as representatives of civil society (among them is the umbrella organization that has been mentioned before in the text). In addition, debates and discussion forums that we have visited have been dominated by core and semi-core organizations. We argue that the reason for this can be traced to the same social network structure that facilitated the protection of the park. Thus, an important emergent hypothesis is that network structures that facilitate protection of ecosystems, might at the same time hinder collaborative management of the same ecosystems.
To explain this, we argue that the movement's coreperiphery structure also structured collaborative arenas, in two ways. Firstly, core and semi-core actors-faciliated through the structure-interacted more actively with authorities and came to be seen as good representatives of civil society; the Ecopark movement, or more correctly the umbrella organization, was (incorrectly) viewed as a homogenous community of organizations. Although this approach seems to have worked in other cases -recall the centralized structure reported by Hahn et al. (2006) in which a bridging organization linked user groups to joint decision-making arenas-it seems not to have worked here. The reason, we believe, lies in how the core-periphery structure secondly came to influence the framing of values that ought to have highest priority on collaborative arenas. We trace this to the early 1990s when the park's identity - facilitated by its royal heritagewas constructed on the pillars of cultural history and conservation biology. This framing process was dominated by core and semi-core actors through their advantageous structural position (as we have seen), whereas user groups were peripheral and had less influence on this process. Consequently, the value of the park as a space for their user activities, tends to have been downplayed (Ernstson and Sörlin 2009). In fact, intensive use of the park was seen as a potential threat by core and semi-core organizations (Ernstson and Sörlin 2009) as it could erode "their" values based on cultural history and conservation biology. This conflict of values seems to further explain the segmentation of heavy users -allotment gardens and boating clubs-in Fig. 3. In contrast to castles and planned English parks, these groups leave behind small huts, chicken-wire fences, and landing stages that might be deemed out of place, unimportant, or just disturbing. A core activist also expressed that boating clubs make it difficult for bird watchers and other nature enthusiasts to follow the shoreline, whereas a boating club chairman expressed that they felt excluded from the park's cultural history, although "we have been here for more than a hundred years." This segmentation has had direct implications as well; when one allotment garden lost plots to development, core and semi-core members remained passive while allotment gardens acted in vain to stop it (Ernstson 2007).

The core-periphery structure has mutually reinforced two crucial processes, that of protecting the park from direct exploitation, and that of creating its identity through framing its values. 
Simultaneously, this has constrained collaborative ecosystem management. More generally, this exemplifies that structures are both facilitative and constraining, or as expressed by Anthony Giddens (1984: 171), "[t]hey serve to open up certain possibilities of action at the same time as they restrict or deny others."

\section{Grounded Speculation}

Social networks are often mentioned as a prerequisite for collaborative management (Carpenter et al. 2001, Olsson et al. 2004a). Most models treat them as either existing or not (Carpenter et al. 2001, Olsson et al. 2004a), or regard them as having "bonding"/"horizontal" links within communities of stakeholders and user groups, and "bridging"/"vertical" links when connecting to authorities (Newman and Dale 2005). Our case of the Stockholm National Urban Park demonstrates that these models may be too simplistic. Although a social network exists, connecting stakeholders, user groups, and authorities, it is not obvious if and how this entails an advantage. Instead we need to analyze the structure of social networks and address their inherent dual nature (Diani 2003a). The same structure that helps protect the park and sustain ecosystem functioning, could simultaneously constrain collaborative ecosystem management. This is of real importance when discussing bridging organizations that link over various scales and connect politics and ecosystems. Adger et al. (2005) suggest that such cross-scale links are determined by power relations in which "more powerful actors can tilt the playing field [in resource management institutions] such that information and knowledge are further skewed in their favor." Our analysis, shows that even community and civil-society actors can tilt the playing field, and that their networks should also be treated as highly structured, in which some actors have more influence than others.

This also relates our study to studies of adaptive capacity. In their review of research on adaptive governance, Folke et al. (2005) identified social memory-defined as the arena to capture experience of ecosystem change actualized through community debate and decision making - as a source of resilience that "key persons" can use to guide and frame collective action in times of crisis and reorganization (also Barthel 2006 pers. comm.). A more critical stance would wonder how this social memory was constituted, who constructs it, and who uses it (Halbwachs 1952/1992). As we have shown, core and semi-core actors in the Ecopark movement - sometimes in alliance with authorities-have been central in decision making and in constructing the identity of the park, resembling social memory. For us, this points out that social memory should also be treated as an outcome of power relations. Consequently, if social memory gets activated to frame activity in times of crisis, the whole issue of adaptive capacity becomes a political issue where some actors will shape the unfolding collective action to benefit themselves more than others (Halbwachs 1952/1992, Melucci 1996, Boström 2004). On a systemic level, the domination of some actors-state agencies and/or civil-society organizations - can come to work as a conservative force by locking certain landscapes into a certain identity that could hinder experimentation and decrease adaptive capacity (Gunderson and Holling 2002). This resonates with social theory where system reproduction is more seen as the result of "selective 'information filtering' whereby strategically placed actors" seek to regulate the system to keep things as they are or to change them (Giddens 1984: 27). Therefore, we argue, following Adger et al. (2005), for a broader and deeper engagement with issues of power in analyzing adaptive capacity in socialecological systems, especially those aspects through which social memory gets constituted and enacted.

\section{CONCLUSION}

We have shown that the core-periphery structure of the Ecopark movement's social network plays a crucial role in protecting the Stockholm National Urban Park from exploitation, and thus in securing ecosystem services generated in the area. We argue that high organizational diversity is an important factor for increasing this green area's protective capacity, but diversity is not sufficient. Instead it is the structure of that diversity that underpins collective action and the social mechanisms important for stopping both large- and small-scale development. The dense social arena of politically active organizations is needed to develop and sustain methods for stopping large-scale development, whereas links to user groups in the landscape are important for stopping smaller-scale development that would otherwise be overlooked. However, we have also shown that the same structure that helped protect the park and sustain ecosystem functioning, could simultaneously have constrained collaborative 
ecosystem management. In particular, user groups with valuable local ecological knowledge have not been included in collaborative arenas. We traced this to their peripheral position in the network structure, especially during the early framing process of the park's identity that was tilted-by core and semi-core actors-toward singular aesthetical and nature preservation ideals, rather than active use. This shows that collaborative ecosystem management is not just about knowledge (as generally treated in literature), but about values as well. And how and by whom (through interaction in social networks) knowledge and values become constructed and interlinked (cf. Emirbayer and Goodwin 1994). Therefore, we recommend authorities and other actors interested in initiating collaborative management aim at empowering user groups. This might be done by using the scientific discourse on local ecological knowledge to show other actors that local user groups have important knowledge.

Our study, therefore, points to theoretical developments. Along with others (Crona and Bodin 2006), we argue that analysts of ecosystem management will benefit greatly from assessing the structures of social networks. This will increase the explanatory power of the analysis and take analysts closer to many of the social mechanisms that collaborative ecosystem management seeks and depends upon, like collective action (Ostrom 1990), social learning (Holling 1978, Pahl-Wostl et al. 2007), trust (Hahn et al. 2006), and social memory (Folke et al. 2005), which are all intertwined with social network structure (Bodin et al. 2006 and references therein). We propose that assessing the social network structure could follow as a complementary step in methods used for identifying actors linked to ecosystems, and we would like to emphasize that there are various other methods to generate social network data (Marsden 1990, Wasserman and Faust 1994, International Network of Social Network Analysis (INSNA) 2008).

The Ecopark movement represents an interesting phenomenon in linking ecology and politics, and in producing large-scale transformation of governance structures. Given the rapid worldwide urbanization (United Nations 2005) and its deteriorating effect on ecosystem services (McGranahan et al. 2005), this phenomenon should be followed up by researchers in natural resource management and sociology alike. There is, however, a need for a more critical perspective on a larger spatial scale as, for instance, the exceptionally high protective capacity of the National Urban Park translocates development pressures to other areas so that distant neigborhoods may lose their green areas instead (cf. Harvey 1996, Heynen 2003). Furthermore, if these lost green areas are crucial in regional ecological networks, such effects could influence ecosystem functioning at larger spatial scales (Andersson and Bodin, unpublished manuscript). In light of this: What seeds of transformative capacity for creating sustainable cities reside in civil society? What hopes are there that these transformations will also produce more equal societies and cities, and not just reproduce, or even strengthen, already existing inequalities in the face of rapid change? Social network theory and social movement theory can prove helpful in addressing these questions and in improving theories and applications of collaborative ecosystem management in urban areas and beyond.

Responses to this article can be read online at:

http://www.ecologyandsociety.org/voll3/iss2/art39/responses/

\section{Acknowledgments:}

We gratefully acknowledge all interview persons and all respondents for taking the time to answer our questions. The first author would like to give special thanks to Örjan Bodin for valuable aid in parts of the network analysis, and Stephan Barthel for data that helped constructing the recall list for the network survey. Also John Parker, Christofer Edling, Miriam Huitric, Victor Galaz, Sophie Oldfield, and two anonymous reviewers contributed with valuable comments. We also thank FORMAS, The Swedish Research Council for Environment, Agricultural Sciences and Spatial Planning, for funding this research. The study has been part of the United Nations' Millennium Ecosystem Assessment.

\section{LITERATURE CITED}

Abrahamson, E., and L. Rosenkopf. 1997. Social network effects on the extent of innovation diffusion: a computer simulation. Organization Science 8(3):289-309.

Adger, N. W., K. Brown, and E. L. Tompkins. 2005. The political economy of cross-scale 
networks in resource co-management. Ecology and Society 10(2):9. [online] URL: http://www.ecology andsociety.org/vol10/iss2/art9/.

Alberti, M., and J. M. Marzluff. 2004. Ecological resilience in urban ecosystems: linking urban patterns to human and ecological functions. Urban Ecosystems 7:241-265.

Andersson, E., S. Barthel, and K. Ahrné. 2007. Measuring social-ecological dynamics behind the generation of ecosystem services. Ecological Applications 17(5):1267-1278.

Ansell, C. K. 2003. Community embeddedness and collaborative governance in the San Francisco Bay Area Environmental Movement. Pages 123-144 in M. Diani and D. McAdam, editors. Social movements and networks - relational approaches to collective action. Oxford University Press, Oxford, UK.

Armitage, D. 2007. Adaptive capacity and community-based natural resource management. Environmental Management 35(6):703-715.

Barthel, S., J. Colding, T. Elmqvist, and C. Folke. 2005. History and local management of a biodiversity-rich, urban, cultural landscape. Ecology and Society 10(2):10. [online] URL: http:/ /www.ecologyandsociety.org/vol10/iss2/art10/.

Berkes, F., C. Folke, and J. Colding, editors. 2003. Navigating social-ecological systems: building resilience for complexity and change. Cambridge University Press, Cambridge, UK.

Bodin, Ö., B. Crona, and H. Ernstson. 2006. Social networks in natural resource management: what is there to learn from a structural perspective? Ecology and Society 11(2):r2. [online] URL: http:// www.ecologyandsociety.org/vol11/iss2/resp2/.

Bodin, Ö., and J. Norberg. 2005. Information network topologies for enhanced local adaptive management. Environmental Management 35 (2):175-193.

Bolund, P., and S. Hunhammar. 1999. Ecosystem services in urban areas. Ecological Economics 29:293-301.

Borgatti, S. P., and M. G. Everett. 1999. Models of core/periphery structures. Social Networks 21:375-395.
Borgatti, S. P., and P. C. Foster. 2003. The network paradigm in organizational reserach: a review and typology. Journal of Management 29(6):991-1013.

Borgström, S., T. Elmqvist, P. Angelstam, and C. Alfsen-Norodom. 2006. Scale mismatches in management of urban landscapes. Ecology and Society 11(2):16. [online] http://www.ecologyands ociety.org/vol11/iss2/art16/.

Boström, M. 2004. Cognitive practices and collective indenties within a heterogenous social movement: the Swedish environmental movement. Social Movement Studies 3(1):73-88.

Burt, R. S. 2003. The social capital of structural holes. Pages 148-189 in M. F. Guillen, R. Collins, P. England, and M. Meyer, editors. The new economic sociology: developments in an emerging field. Russell Sage Foundation, New York, New York, USA.

Burt, R. S. 2005. Brokerage and closure: an introduction to social capital. Oxford University Press, Oxford, UK.

Carpenter, S., B. Walker, J. M. Anderies, and N. Abel. 2001. From metaphor to measurement: resilience of what to what? Ecosystems 4(8):765781.

Castells, M. 1983. The city and the grassroots. E. Arnold, London, UK.

Chiesura, A. 2004. The role of urban parks for the sustainable city. Landscape and urban planning 68:129-138.

Colding, J. 2006. "Ecological land-use complementation" for building resilience in urban ecosystems. Landscape and Urban Planning (doi:10.1016/j. landurbplan.2006.10.016).

Colding, J., J. Lundberg, and C. Folke. 2006. Incorporating green-area user groups in urban ecosystem management. Ambio 35(5):237-244.

Crona, B., and Ö. Bodin. 2006. What you know is who you know? Communication patterns among resource users as a prerequisite for co-management. Ecology and Society 11(2):7. [online] http://www.e cologyandsociety.org/vol11/iss2/art7/.

Daily, G. C., editor. 1997. Nature's services: 
societal dependence on natural ecosystems. Island Press, Washington, D.C., USA.

Dale, A., and J. Onyx, editors. 2005. A dynamic balance. University of British Columbia Press, Vancouver, British Columbia, Canada.

Degenne, A., and M. Forsé. 1999. Introducing social networks. Sage Publications, London, UK.

della Porta, D., and M. Diani. 2006. Social movements: an introduction. Blackwell Publishing, Oxford, UK.

Diani, M. 1992. The concept of social movement. Sociological Review 40:1-25.

Diani, M. 1995. Green networks. Edinburgh University Press, Edinburgh, UK.

Diani, M. 2003a. Introduction: social movements, contentious actions, and social networks: 'from metaphor to substance'? Pages 1-18 in M. Diani and D. McAdam, editors. Social movements and networks: relational approaches to collective action. Oxford University Press, Oxford, UK.

Diani, M. 2003b. "Leaders" or brokers? Positions and influence in social movement networks. Pages 105-122 in M. Diani and D. McAdam, editors. Social movements and networks: relational approaches to collective action. Oxford University Press, Oxford, UK.

Diani, M. 2003c. Networks and social movements: a reserach programme. Pages 299-319 in M. Diani and D. McAdam, editors. Social movements and networks: relational approaches to collective action. Oxford University Press, Oxford, UK.

Diani, M., and D. McAdam, editors. 2003. Social movements and networks: relational approaches to collective action. Oxford University Press, Oxford, UK.

Drayton, B., and R. B. Primack. 1996. Plant species lost in an isolated conservation area in Metropolitan Boston from 1894-1993. Conservation Biology 10(1):30-39.

Elmqvist, T., J. Colding, S. Barthel, S. Borgström, A. Duit, J. Lundberg, E. Andersson, K. Ahrné, H. Ernstson, C. Folke, and J. Bengtsson. 2004. The dynamics of social- ecological systems in urban landscapes: Stockholm and the National Urban Park, Sweden. Annual New York Academy of Science 1023:308-322.

Emirbayer, M., and J. Goodwin. 1994. Network analysis, culture and the problem of agency. American Journal of Sociology 99:1411-1454.

Ernstson, H. 2007. The drama of urban greens and regimes: social movements and ecosystem services in Stockholm National Urban Park. Licentiate in Philosophy Thesis, Stockholm University, Stockholm, Sweden.

Ernstson, H. 2008. In rhizomia: actors, networks and resilience in urban landscapes. Dissertation, Stockholm University, Stockholm, Sweden. [online] URL: http://urn.kb.se/resolve?urn=urn:nbn: se:su:diva-8137.

Ernstson, H., and S. Sörlin. 2009. Weaving protective stories: connective practices to articulate holistic values in Stockholm National Urban Park. Environment and Planning A: in press.

Fabricius, C., C. Folke, G. Cundill, and L. Schultz. 2007. Powerless spectators, coping actors, and adaptive co-managers: a synthesis of the role of communities in ecosystem management. Ecology and Society 12(1):29. [online] URL: http://www.ec ologyandsociety.org/vol12/iss1/art29/.

Folke, C., T. Hahn, P. Olsson, and J. Norberg. 2005. Adaptive governance of social-ecological systems. Annual Review of Environment and Resources 30:441-473.

Freeman, L. 1979. Centrality in social networks. Conceptual clarifications. Social Networks 1:215239.

Gadgil, M., P. Olsson, F. Berkes, and C. Folke. 2003. Exploring the role of local ecological knowledge in ecosystem management: three case studies. Pages ??? in F. Berkes, J. Colding, and C. Folke, editors. Navigating social-ecological systems: building resilience for complexity and change. Cambridge University Press, Cambridge, UK.

Giddens, A. 1984. The constitution of society: outline of the theory of structuration. Polity Press, Cambridge, UK. 
Girvan, M., and M. E. J. Newman. 2002. Community structure in social and biological networks. Proceedings of the National Academy of Sciences 99(12):7821-7826. [online] URL: http://w ww.pnas.org/cgi/content/abstract/99/12/7821.

Granovetter, M. 1973. The strength of weak ties. American Journal of Sociology 76(6):1360-1380.

Granovetter, M. 1985. Economic action and social structure: the problem of embeddedness. American Journal of Sociology 91:481-510.

Grimm, N. B., J. M. Grove, S. T. A. Pickett, and C. L. Redman. 2000. Integrated approaches to long-term studies of urban ecological systems. Bioscience 50(7):571-583.

Gunderson, L. H. 1999. Resilience, flexibility and adaptive management - antidotes for spurious certitude? Conservation Ecology 3(1):7. [online] URL: http://www.ecologyandsociety.org/vol3/iss1/ $\underline{\operatorname{art} 7 / .}$

Gunderson, L. H., and C. S. Holling, editors. 2002. Panarchy: understanding transformations in human and natural systems. Island Press, Washington, D.C., USA.

Hahn, T., P. Olsson, C. Folke, and K. Johansson. 2006. Trust-building, knowledge generation and organizational innovations: the role of a bridging organization for adaptive comanagement of a wetland landscape around Kristianstad, Sweden. Human Ecology 34:573-592.

Halbwachs, M. 1952/1992. On collective memory. University of Chicago Press, Chicago, Illinois, USA.

Harvey, D. 1996. Justice, nature and the geography of difference. Blackwell, Oxford, UK.

Heynen, N. C. 2003. The scalar production of injustice within the urban forest. Antipode :980998.

Holling, C. S. 1978. Adaptive environmental assessment and management. John Wiley, New York, New York, USA.

International Network of Social Network Analysis (INSNA). 2008. Homepage of International Network of Social Network Analysis. [online] http ://www.insna.org. (Accessed 1 June 2008.) in.
Leavitt, H. 1951. Some effects of certain communication patterns on group performance. Journal of Abnormal and Social Psychology 46:3850.

Lorrain, F., and H. C. White. 1971. Structural equivalence of individuals in social networks. Journal of Mathematical Sociology 1:49-80.

Lowe, P. D., and J. M. Goyder. 1983. Environmental groups in politics. Allen and Unwin, London, UK.

Löfvenhaft, K. 2002. Spatial and temporal perspectives on biodiversity for physical planning: examples from urban Stockholm, Sweden. Dissertation, Stockholm University, Stockholm, Sweden.

Millennium Ecosystem Assessment. 2005. Millennium ecosystem assessment: biodiversity synthesis. World Resources Institute, Washington, D.C., USA.

Marsden, P. V. 1990. Network data and measurement. Annual Review of Sociology 16:435463.

McAdam, D., J. D. McCarthy, and M. N. Zald, editors. 1996. Comparative perspectives on social movements. Political opportunities, mobilizing structures, and cultural framings. Cambridge University Press, Cambridge, UK.

McCarthy, J. D., and M. N. Zald. 1977. Resource mobilization and social movements: a partial theory. American Journal of Sociology 82(6): 12121241.

McGranahan, G., P. Marcotullio, X. Bai, D. Balk, T. Braga, I. Douglas, T. Elmqvist, W. Rees, D. Satterthwaite, J. Songsore, H. Zlotnick, J. Eades, E. Ezcurra, and A. Whyte. 2005. Urban systems. Pages 795-825 in Hassan, R., R. Scholes, and N. Ash, editors. Ecosystems and Human Well-being: Current State and Trends, Volume 1. Island Press, Washington, D.C., USA.

Melucci, A. 1995. The process of collective identity. Pages 41-63 in H. Johnston and B. Klandermans, editors. Social movements and culture. University of Minnesota Press, Minneapolis, Minnesota, USA. 
Melucci, A. 1996. Challenging codes. collective action in the Information Age. Cambridge University Press, Cambridge, UK.

Miller, B. 2000. Geography and social movements. University of Minnesota Press, Minneapolis, Minnesota, USA.

National Parliament. 1994-1995. Parliamentary proposition 1994/95:3 handed in by Swedish Government, Sveriges riksdag, SE-100 12 Stockholm. Name: Riksdagsproposition 1994/95:3: Nationalstadsparken Ulriksdal-Haga-BrunnsvikenDjurgården (The National Urban Park). Government of Sweden, Stockholm, Sweden.

Newman, L., and A. Dale. 2005. Network structure, diversity, and proactive resilience Bbuiliding: a response to Tompkins and Adger. Ecology and Society 10(1):r2. [online] URL: http:// www.ecologyandsociety.org/vol10/iss1/resp2/.

Nyström, M., and C. Folke. 2001. Spatial resilience of coral reefs. Ecosystems 4:406-417.

Olsson, P., and C. Folke. 2001. Local ecological knowledge and institutional dynamics for ecosystem management: a study of Lake Racken watershed, Sweden. Ecosystems 4(2):85-104.

Olsson, P., C. Folke, and F. Berkes. 2004a. Adaptive comanagement for building resilience in social-ecological systems. Environmental Management 34(1):75-90.

Olsson, P., C. Folke, and T. Hahn. 2004b. Socialecological transformation for ecosystem management: the development of adaptive co-management of a wetland landscape in Southern Sweden. Ecology and Society 9:(4): 2. [online] URL: www.ecologya ndsociety.org/vol9/iss4/art2.

Ostrom, E. 1990. Governing the commons: the evolution of institutions for collective action. Cambridge University Press, Cambridge, UK.

Pahl-Wostl, C., M. Craps, A. Dewulf, E. Mostert, D. Tabara, and T. Taillieu. 2007. Social learning and water resources management. Ecology and Society 12(2):5. [online] URL: http://www.ecology andsociety.org/vol12/iss2/art5/.

Reagans, R., and B. McEvily. 2003. Network structure and knowledge transfer: the effects of cohesion and range. Administrative Science Quarterly 48(2):240-267.

Redman, C. L., J. M. Grove, and L. H. Kuby. 2004. Integrating social science into the Long-Term Ecological Research (LTER) Network: social dimensions of ecological change and ecological dimensions of social change. Ecosystems 7(2):161171.

Sandström, U. G., P. Angelstam, and A. Khakee. 2006. Urban comprehensive planning_-identifying barriers for the maintenance of functional habitat networks. Landscape and Urban Planning 75:4357.

Schwartz, M. W., editor. 1997. Conservation in highly fragmented landscapes. Chapman and Hall, New York, New York, USA.

Snow, D., B. J. Rochford, S. Worden, and R. Benford. 1986. Frame alignment processes, micromobilization, and movement participation. American Sociological Review 51:464-481.

Stahre, U. 2004. Den gröna staden (The green city). Atlas, Stockholm, Sweden.

Stenhouse, R. N. 2004. Fragmentation and internal disturbance of native vegetation reserves in the Perth metropolitan area, Western Australia. Landscape and Urban Planning 68:389-401.

United Nations (UN). 2005. World urbanization prospects: the 2005 revision. United Nations Population Division, New York, New York, USA.

Wasserman, S., and K. Faust. 1994. Social network analysis-methods and applications. Cambridge University Press, Cambridge, UK.

Weimann, G. 1982. On the importance of marginality: one more step into the two-step flow of communication. American Sociological Review 47(6):764-773.

Wenger, E. 1998. Communities of practice: learning, meaning, and identity. Cambridge University Press, New York, New York, USA.

White, D. R., and M. Houseman. 2002. The navigability of strong ties: small worlds, tie strength, and network topology. Complexity 8 (1):72-81. 
Young, C. H., and J. Jarvis. 2001. A simple method for predicting the consequences of land management in urban habitats. Environmental Management 28(3):375-387. 
Appendix 1. Methodology and Data Analysis

Please click here to download file 'appendix1.pdf'. 


\section{Appendix 2. Tables and Figures}

\section{Please click here to download file 'appendix2.pdf'.}

